\title{
Sustainable Construction-High Performance Concrete Containing Limestone Dust as Filler
}

\author{
Tahir Kibriya ${ }^{1 *}$, Leena Tahir ${ }^{2}$ \\ ${ }^{1}$ Senior Consulting Engineer, Black \& Veatch, Toronto, Canada (ex Faculty/Head of Civil Engineering Department, NUST, Risalpur, \\ Pakistan) \\ ${ }^{2} \mathrm{MSc}$ Structural Engineering, City University, London, UK \\ Email ^t_kibriya@yahoo.com
}

How to cite this paper: Kibriya, T. and Tahir, L. (2017) Sustainable ConstructionHigh Performance Concrete Containing Limestone Dust as Filler. World Journal of Engineering and Technology, 5, 404-411. https://doi.org/10.4236/wjet.2017.53034

Received: May 15, 2017

Accepted: July 14, 2017

Published: July 17, 2017

Copyright (c) 2017 by authors and Scientific Research Publishing Inc. This work is licensed under the Creative Commons Attribution International License (CC BY 4.0).

http://creativecommons.org/licenses/by/4.0/

(c) (i) Open Access

\begin{abstract}
Massive amounts of limestone waste are produced by the stone processing industry worldwide. Generally, it is believed that $60 \%$ to $70 \%$ of the stone is wasted in processing in the form of fragments, powder and slurry out of which around $30 \%$ is in the form of fine powder [1]. This waste has no beneficial usage and poses environmental hazards. Use of this waste product in the construction industry can largely reduce the amount of waste to be disposed off by the local municipalities in addition to reducing large burden on the environment. Some basic research on use of limestone dust as cement/ concrete filler has been carried out in the recent past but high strength/ high performance concretes have not been investigated yet [2] [3]. The concrete industry is among the largest consumer of raw materials worldwide and has been investigated for use of various types of waste materials like crushed brick, rice husk and straw ash as either aggregates for concrete or as partial cement substitutes. Use of limestone dust as filler material in concrete can consume a huge amount of this waste material which has to be disposed off otherwise, creating large burden on the environment. This experimental study aimed at evaluating the properties of high performance concretes made from Portland cement, natural aggregates and sand. Limestone dust was added by replacing sand in the percentages of $10 \%$ and $20 \%$. Wide ranging investigations covering most aspects of mechanical behavior and permeability were carried out for various mixes for compressive strengths of $60 \mathrm{~N} / \mathrm{mm}^{2}, 80 \mathrm{~N} / \mathrm{mm}^{2}$ and $100 \mathrm{~N} / \mathrm{mm}^{2}$. Compressive strengths of concrete specimen with partial replacement of sand with $10 \%$ and $20 \%$ limestone dust as filler material for $60 \mathrm{~N} / \mathrm{mm}^{2}, 80 \mathrm{~N} / \mathrm{mm}^{2}$ and $100 \mathrm{~N} / \mathrm{mm}^{2}$ were observed to be higher by about $4 \%$ to $12 \%$ than the control specimen. Flexural strengths were also observed to be higher by $12 \%$ $13 \%$. Higher elastic moduli and reduced permeability were observed along with better sulphate and acid resistance. Better strengths and improved durability of such high-performance concretes make it a more acceptable material
\end{abstract}


for major construction projects.

\section{Keywords}

Limestone Dust, Filler, Sustainable Construction, Construction Waste, High Strength Concrete, Cement Filler

\section{Introduction}

The quality of concrete has improved tremendously over the recent years due to ongoing research on newer materials and chemicals. High performance concretes with improved strengths and durability are readily available in the markets. Scarcity of natural aggregates and cement manufacturing raw materials has led to exploration of cheaper alternatives worldwide. Furthermore, sustainable and emerging green practices leading to environmentally friendly materials have led to use of many waste materials in manufacturing of cement and concrete. These have led to newer avenues especially in the developing/under developed countries where resource crunch is a major hurdle towards development. A number of studies have been carried out to find better/cheaper aggregates and cements along with better usage of waste materials in construction [4]-[11].

Massive amounts of limestone and marble are quarried and used worldwide for various purposes. Marble is a refined form of limestone and dolomite formed by their metamorphism. During cutting and sawing process of limestone, huge amounts of fragments, fine powder and slurry are generated as waste product. Generally, it is believed that $60 \%$ to $70 \%$ of the stone is wasted in this process in the form of fragments, powder and slurry out of which around $30 \%$ is in the form of fine powder [1]. Large quantities of limestone processing waste worldwide poses disposal problems since it has no beneficial usage. Use of limestone dust waste in production of concretes for major construction projects will certainly reduce the costs and will hence result into cheaper construction and improved durability. Bulk use of this waste material can consume large quantities in construction industry, thereby reducing the burden on the environment in addition to producing environment friendly concrete. In the absence of any worthwhile research in this field, this study was undertaken to assess the properties of concretes produced by using limestone dust as partial fines replacement.

\section{Research Significance}

The significance of this research is to investigate the possible use of an abundantly available waste product in construction industry thereby solving its disposal problems along with possibility of obtaining a better product i.e. high performance concrete with improved characteristics. Environment is benefitted as a consequence.

\section{Mix Design}

Mix design for three high strength concrete mixes was carried out based on 
Table 1. Design of concrete mixes.

\begin{tabular}{ccccccc}
\hline $\begin{array}{c}\text { Characteristic } \\
\text { Strength N/mm }\end{array}$ & $\begin{array}{c}\text { W/C } \\
\text { Ratio }\end{array}$ & $\begin{array}{c}\text { Cement } \\
\mathrm{kg}\end{array}$ & $\begin{array}{c}\text { Sand } \\
\mathrm{kg}\end{array}$ & $\begin{array}{c}\text { Water } \\
\mathrm{kg}\end{array}$ & $\begin{array}{c}\text { Aggregate } \\
\mathrm{kg}\end{array}$ & $\begin{array}{c}\text { Super } \\
\text { Plasticizer }\end{array}$ \\
\hline 60 & 0.3 & 460 & 511 & 135 & 1330 & $7.41 / \mathrm{m}^{3}$ \\
80 & 0.24 & 570 & 479 & 135 & 1265 & $9.81 / \mathrm{m}^{3}$ \\
100 & 0.2 & 690 & 440 & 135 & 1151 & $15.31 / \mathrm{m}^{3}$ \\
\hline
\end{tabular}

Design of Normal Concrete Mixes method of Department of EnvironmentTransport and Road Research Laboratory, London, UK [12]. Linear projection of compressive strength versus w/c ratio from Design of Normal Concrete Mixes method was considered beyond the limiting w/c ratio of 0.3 . Characteristic strengths selected for the trial concrete mixes were 60,80 and $100 \mathrm{~N} / \mathrm{mm}^{2}$. These mixes were designed using ordinary Portland cement, crushed limestone coarse aggregates (maximum $37.5 \mathrm{~mm}$ diameter) and medium grade sand partially replaced with $10 \%$ and $20 \%$ limestone dust. Control mix contained $100 \%$ medium sand. Limestone dust used was $100 \%$ passing \#100 sieves. An initial estimate of density was made and later adjusted in the light of values actually obtained by the mix design method. The details of the quantities of materials used in the mixes are given in Table 1. Around 1\% of super plasticizer with a maximum of 15.1 $1 / \mathrm{m}^{3}$ was used to maintain workability and slump in the range of 90 to $120 \mathrm{~mm}$.

\section{Testing of Concrete}

Three specimens each from three different batches were used in all tests. Tests and specimen used for different tests were as follows:

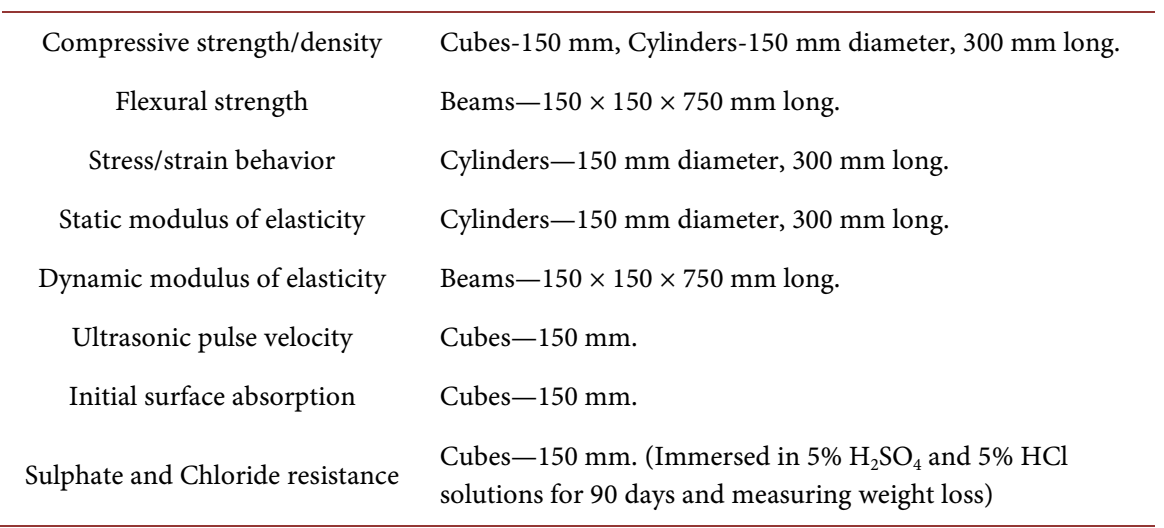

All specimens were cured in water at $20^{\circ} \mathrm{C}$ for 28 days before testing.

\section{Discussion of Test Results}

The properties of the high-performance concretes produced are summarized in Table 2 and Table 3.

\subsection{Compressive Strength}

Compressive strength tests on cubes at $7 \& 28$ days showed that the rate of 
Table 2. Properties of concrete.

\begin{tabular}{|c|c|c|c|c|c|}
\hline $\begin{array}{l}\text { W/C } \\
\text { Ratio }\end{array}$ & Mixes & $\begin{array}{l}\text { Cube Strength } \\
7 \text { Days N/mm }{ }^{2}\end{array}$ & $\begin{array}{l}\text { Cube Strength } \\
28 \text { Days N/mm² }\end{array}$ & $\begin{array}{c}\text { Cylinder Strength } \\
\qquad \mathrm{N} / \mathrm{mm}^{2}\end{array}$ & $\begin{array}{l}\text { Flexural Strength } \\
\qquad \mathrm{N} / \mathrm{mm}^{2}\end{array}$ \\
\hline \multirow{3}{*}{0.3} & Control & 51 & 63 & 53.5 & 6.4 \\
\hline & A & 54 & 68 & 56 & 7.3 \\
\hline & B & 56 & 71 & 59 & 8 \\
\hline \multirow{3}{*}{0.24} & Control & 73 & 82 & 66 & 7.9 \\
\hline & A & 74 & 84 & 74 & 9 \\
\hline & B & 76 & 87 & 76 & 10.8 \\
\hline \multirow{3}{*}{0.2} & Control & 92 & 103 & 86 & 9.8 \\
\hline & A & 91 & 105 & 88 & 11 \\
\hline & B & 94 & 107 & 90 & 11.9 \\
\hline
\end{tabular}

Control-100\% Medium Sand; A-10\% Sand replaced with limestone dust; B-20\% Sand replaced with limestone dust.

Table 3. Properties of concrete.

\begin{tabular}{cccccc}
\hline W/C Ratio & Mixes & ISAT ml/m²/s & $\begin{array}{c}\text { Elastic Modulus } \\
\mathrm{N} / \mathrm{mm}^{2}\end{array}$ & $\begin{array}{c}\text { Dynamic Modulus } \\
\mathrm{N} / \mathrm{mm}^{2}\end{array}$ & $\begin{array}{c}\text { Pulse Velocity } \\
\mathrm{km} / \mathrm{s}\end{array}$ \\
\hline \multirow{3}{*}{0.3} & Control & 0.22 & 36,870 & 51,378 & 4.7 \\
& A & 0.18 & 37,220 & 54,145 & 5.0 \\
& B & 0.17 & 38,395 & 56,610 & 5.2 \\
\multirow{2}{*}{0.24} & Control & 0.20 & 37,200 & 54,563 & 4.8 \\
& A & 0.16 & 38,750 & 57,490 & 5.1 \\
& B & 0.15 & 39,460 & 59,194 & 5.3 \\
0.2 & Control & 0.17 & 38,220 & 56,684 & 4.8 \\
& A & 0.14 & 39,080 & 57,690 & 5.2 \\
& B & 0.13 & 40,620 & 57,954 & 5.4 \\
\hline
\end{tabular}

development of strength of concrete specimen containing $10 \%$ and $20 \%$ sand replaced with limestone dust was similar to normal concrete samples. The compressive strengths of high performance concrete with $10 \%$ and $20 \%$ sand replaced with limestone dust was higher than the control specimen varying between $4 \%$ to $12 \%$ with higher range for $20 \%$ sand replacement with limestone dust. Since low w/c ratios require lot of external water for hydration, it was observed that the compressive strengths of test samples kept increasing with time [13]. High performance concrete with $10 \%$ and $20 \%$ sand replaced with limestone dust both developed $80 \%$ to $85 \%$ of its 28 day characteristic strength in 7 days like normal concretes. During the testing, it was observed that the complete section of high performance concrete specimen tends to fail suddenly and explosively which is typical of high strength concretes [13]. Protective measures must be taken to prevent any damage due to such sudden failure of test specimen. To maintain safety from the explosive failure of high strength concrete specimen, a 
lower loading rate of 0.15 to $0.2 \mathrm{~N} / \mathrm{mm}^{2} / \mathrm{s}$ was maintained during the testing as compared to 0.2 to $0.4 \mathrm{~N} / \mathrm{mm}^{2}$ specified by BS1881:Part 116:1983. Table 2 gives the compressive strengths of the samples as well as the control specimen.

\subsection{Flexural Strength}

The flexural strength of high performance concrete with $10 \%$ sand replaced with limestone dust as well as specimen containing $20 \%$ sand replaced with limestone dust both were observed to be higher by $12 \%$ to $13 \%$ as compared to control specimen. Higher flexural strengths are certainly a consequence of higher compressive strength and increased density of concrete with $10 \%$ and $20 \%$ sand replaced with limestone dust as compared to the control mixes as shown in Table 2.

\subsection{Stress/Strain Behavior}

It was observed that the general slope of the stress/strain curve for high performance concrete with $10 \%$ sand replaced with limestone dust as well as specimen containing $20 \%$ sand replaced with limestone dust both were similar to the curve for control specimen. All the curves were observed to be virtually linear up to the point of failure which is typical of high strength concretes. Higher static and dynamic moduli of elasticity were observed for high strength concretes with $10 \%$ sand replaced with limestone dust as well as specimen containing $20 \%$ sand replaced with limestone dust both. Values for static and dynamic moduli are given in Table 3 while idealized stress/strain relationships for all samples are shown in Figure 1.

\subsection{Static Modulus of Elasticity}

Values for Static Modulus of Elasticity for high strength concrete with specimen containing $20 \%$ sand replaced with limestone dust was observed to be about 4 to

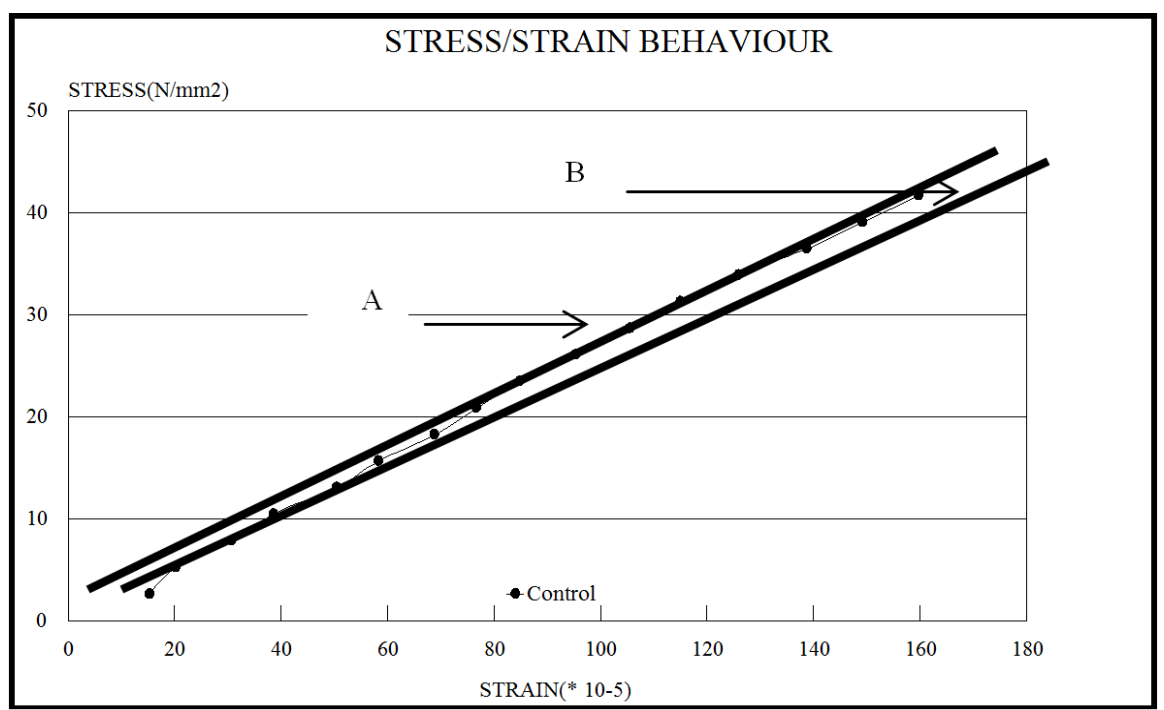

Control-100\% Medium Sand; A-10\% Sand replaced with limestone dust; B-20\% Sand replaced with limestone dust.

Figure 1. Idealized Stress-Strain Curves. 
$5 \%$ higher than the control specimen. For concrete with $10 \%$ sand replaced with limestone dust, the Static Modulus of Elasticity was observed to be 2\% to 3\% higher than the control specimen. Average values for Static Modulus of Elasticity was observed to be vary from 38,000 to $40,000 \mathrm{~N} / \mathrm{mm}^{2}$ for high strength concrete with $20 \%$ sand replaced with limestone dust as compared to 36,800 to 38,000 $\mathrm{N} / \mathrm{mm}^{2}$ for high strength concretes containing $100 \%$ medium sand. The Values for Static Modulus of Elasticity are given in Table 3.

\subsection{Dynamic Modulus of Elasticity}

Dynamic Modulus of Elasticity for concrete with 20\% sand replaced with limestone dust was observed to be $4 \%$ higher than the control as compared to concrete with $10 \%$ sand replaced with limestone dust which was observed to be about 2\% higher than the control specimen. Table 3 gives the values of Dynamic Moduli of Elasticity of various specimen.

\subsection{Ultrasonic Pulse Velocity}

Average pulse velocity across concrete with specimen containing $10 \%$ and $20 \%$ sand replaced with limestone dust was observed to be 5.2 and $5.4 \mathrm{~km} / \mathrm{s} \mathrm{respec-}$ tively as compared to an average velocity of around $4.8 \mathrm{~km} / \mathrm{s}$ for control mixes. Hence ultrasonic pulse velocity in the case of concrete with $10 \%$ and $20 \%$ sand replaced with limestone dust was observed to be $10 \%$ to $12 \%$ higher than the control mixes. Higher pulse velocities are certainly due to better quality, higher density and reduced voids in the high strength concretes containing partial replacement of limestone dust with sand, as compared to the control mixes. The ultrasonic pulse velocities observed for different concretes are given in Table 3.

\subsection{Density of Hardened Concrete}

The average saturated and oven-dried densities for high strength concrete with $10 \%$ and $20 \%$ sand replaced with limestone dust were 2580 and $2490 \mathrm{~kg} / \mathrm{m}^{3}$ respectively, as compared to control mixes which were 2488 and $2461 \mathrm{~kg} / \mathrm{m}^{3}$, respectively. Hence the saturated and dry densities of concrete with $10 \%$ and $20 \%$ sand replaced with limestone dust are about $4 \% \& 2 \%$ higher respectively than the control mixes. Higher densities for concrete with $10 \%$ and $20 \%$ sand replaced with limestone dust are due to better packing of materials in concrete with sand replaced with fine limestone dust. In the presence of higher content of fines and cementitious material and low w/c ratios, most of the unhydrated cementitious material too acts as filler to densify the concrete, whilst the hydration process continues over longer duration.

\subsection{Initial Surface Absorption (ISAT)}

Initial surface absorption for concrete with $20 \%$ sand replaced with limestone dust was observed to be lowest with around $22 \%$ lower whilst for concrete with $10 \%$ sand replaced with limestone dust it was around $19 \%$ low as compared to the control. The values are compared with the guidelines given by the Concrete 
Society Technical Report \# 31 [14]. Results of ISAT are given in Table 3.

\subsection{Sulphate and Chloride Resistance}

For chloride resistance, submersion of specimen in HCL solution resulted in average weight loss of $7 \%$ for control specimen as compared to $3.6 \%$ and $3.2 \%$ for concrete with $10 \%$ and $20 \%$ sand replaced with limestone dust respectively. For sulphate resistance, submersion of specimen in $\mathrm{H}_{2} \mathrm{SO}_{4}$ solution resulted in average weight loss for control specimen as $6 \%$ as compared to $2.7 \%$ and $2 \%$ for specimen containing $10 \%$ and $20 \%$ sand replaced with limestone dust respectively. Hence, the performance of concrete with partial replacement of sand with limestone dust was almost twice better in acidic environment and slightly over twice better in sulphate environment as compared to concrete with ordinary Portland cement control mixes. Better chloride and sulphate resistance for concrete with $10 \%$ and $20 \%$ sand replaced with limestone dust is mainly due to the reduced permeability and higher densities of concrete with partial replacement of sand with limestone dust.

\subsection{Shrinkage}

Shrinkage of all specimen was observed to be similar. No appreciable difference in shrinkage of specimen cast from concrete with partial replacement of sand with limestone dust and control mixes were observed for 90 days.

\section{Conclusion}

The performance of concrete with partial replacement of sand with limestone dust proved to be satisfactory with improved performance. Compressive strengths of $60 / 80 / 100 \mathrm{~N} / \mathrm{mm}^{2}$ can be attained with up to $20 \%$ sand replaced with limestone dust in normal concrete mixes. Better packing, reduced voids, improved workability and better hydration due to fines dispersal in the mix resulted into better performance. $4 \%$ to $12 \%$ higher compressive strengths could be achieved with $10 \%$ and $20 \%$ sand replaced with limestone dust in normal concrete with higher range for $20 \%$ sand replacement with limestone dust. Flexural strength of high performance concrete with $10 \%$ and $20 \%$ sand replaced with limestone dust is observed to be higher by $12 \%$ to $13 \%$ as compared to control specimen. The average static modulus of elasticity for concrete specimen containing $20 \%$ sand replaced with limestone dust was observed to be about $4 \%$ to $5 \%$ higher than the control specimen while for concrete with $10 \%$ sand replaced with limestone dust, it was observed to be $2 \%$ to $3 \%$ higher than the control. The average dynamic modulus of elasticity for concrete with $20 \%$ sand replaced with limestone dust was observed to be $4 \%$ higher than the control as compared to concrete with $10 \%$ sand replaced with limestone dust which was observed to be about $2 \%$ higher. Ultrasonic pulse velocity in the case of concrete with $10 \%$ \& $20 \%$ sand replaced with limestone dust was observed to be $10 \%$ to $12 \%$ higher than the control mixes. Saturated and dry densities of concrete with $10 \%$ \& $20 \%$ sand replaced with limestone dust are about $4 \%$ \& $2 \%$ higher 
respectively than the control mixes. The performance of concrete with partial replacement of sand with limestone dust was almost twice better in acidic environment and slightly over twice better in sulphate environment as compared to concrete with ordinary Portland cement control mixes. There is no appreciable difference in shrinkage of specimen cast from concrete with partial replacement of sand with limestone dust and control mixes were observed for 90 days.

\section{References}

[1] Aukor, F.J. and Al-Qinna, M.I. (2008) Marble and Environmental Constraints: Case study from Zarqa Governorate, Jordan. Jordan Journal of Earth and Environmental Sciences, 1, 11-21.

[2] Binici, H., Kaplan, H. and Yilmaz, S. (2007) Influence of Marble and Limestone Dusts as Additives on Some Mechanical Properties of Concrete. Scientific Research and Essay, 2, 372-379.

[3] Bonavetti, V., Donza, H., Mene'ndez, G., Cabrera, O. and Irassar, E.F. (2003) Limestone Filler Cement in Low w/c Concrete: A Rational Use of Energy. Cement and Concrete Research, 33, 865-871. https://doi.org/10.1016/S0008-8846(02)01087-6

[4] Corinaldesi, V., Moriconi, G. and Naik, T.R. (2010) Characterization of Marble Powder for Its Use in Mortar and Concrete. Construction and Building Materials, 24, 113-117. https://doi.org/10.1016/j.conbuildmat.2009.08.013

[5] Demirel, B. (2010) The Effect of the Using Waste Marble Dust as Fine Sand on the Mechanical Properties of the Concrete. International Journal of the Physical Sciences, 5, 1372-1380.

[6] Kibriya, T. (1991) The Properties of Concrete with Crushed Brick Coarse Aggregates. Dissertation Submitted for Fulfilling Requirement of Ph.D., City University, London.

[7] Kibriya, T. and Speare, P.R.S. (1996) The Use of Crushed Brick Coarse Aggregates in Concrete. International Congress on "Concrete in the Service of Mankind", Dundee, 24-28 June 1996, 495-503.

[8] Kibriya, T. and Baig, N. (2005) High Performance Concrete with Blended Cements Using Agro-Wastes. Proceedings of MCMat 2005, Joint ASCE/ASME/SES Conference on Mechanics and Materials, 1-3 June 2005, Baton Rouge, Louisiana, 112-1-5.

[9] Kibriya, T. and Khan, S. (2005) High Performance Concrete Pavements Using Agro-Waste Blended Cement. Proceedings of MCMat 2005, Joint ASCE/ ASME/SES Conference on Mechanics and Materials, 1-3 Jun, 2005, Baton Rouge, Louisiana, 60-1-4.

[10] Kibriya, T. and Baig, N. (2005) Agricultural Wastes in Construction, Blended Cements Containing Rice Straw Ash. IV Regional Conference on Civil Engineering Technology, Joint ASCE/ ESIE Conference, Cairo, 7-9 June 2005, 1-4.

[11] Kibriya, T. (2006) Performance of Blended Cement in High Strength Self Compacting Concrete. ASCE Structures Congress 2006, Joint ASCE/ SEI Conference, 18-20 May 2006, St Louis, Missouri, 1-7.

[12] Teychenne, D.C., Franklin, R.E. and Erntroy, H.C. (1988) Design of Normal Concrete Mixes. (Replacement to Road Note.4), Department of Environment-Transport and Road Research Laboratory, London.

[13] Nawy, E.G. (1996) Fundamentals of Histrength High Performance Concrete, Longman.

[14] ACI Compilation \# 32, High Performance Concrete. 
Submit or recommend next manuscript to SCIRP and we will provide best service for you:

Accepting pre-submission inquiries through Email, Facebook, LinkedIn, Twitter, etc. A wide selection of journals (inclusive of 9 subjects, more than 200 journals)

Providing 24-hour high-quality service

User-friendly online submission system

Fair and swift peer-review system

Efficient typesetting and proofreading procedure

Display of the result of downloads and visits, as well as the number of cited articles Maximum dissemination of your research work

Submit your manuscript at: http://papersubmission.scirp.org/

Or contact wjet@scirp.org 